\title{
SELF-MEDICATION PRACTICES DURING COVID-19 PANDEMIC: A CROSS-SECTIONAL SURVEY
}

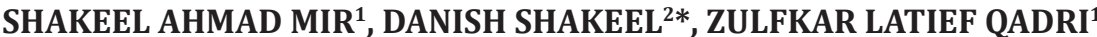

${ }^{1}$ Department of Clinical Pharmacology, Sher-I-Kashmir Institute of Medical Sciences (SKIMS), Srinagar, Kashmir, India. ${ }^{2}$ Department of Computer Science Engineering, University Institute of Engineering Chandigarh University, Mohali, Punjab, India.

Email: danishshakeel54@gmail.com

Received: 30 June 2021, Revised and Accepted: 07 September 2021

\section{ABSTRACT}

Objective: Self-medication is a worldwide practice in which individuals, families, and/or communities choose pharmaceuticals to address health conditions without consulting a doctor. It impacts the health of people both negatively as well as positively. This study aims to determine the prevalence of self-medication for COVID-19 like symptoms during the pandemic.

Methods: This is an online questionnaire-based survey on the perceptions and use of certain drugs for COVID-like symptoms during the COVID-19 pandemic. 168 people responded to the questionnaire.

Results: Out of 168 respondents, $53.0 \%$ were males. $71.4 \%$ were below 30 years of age and, $25.6 \%$ were $31-60$ years. The majority (72.6\%) were unmarried. 50.0\% had studied up to university level. 49.4\% were unemployed. $39.9 \%$ were healthcare workers. 59.9\% had suffered from respiratory symptoms during the COVID-19 pandemic. All those who developed symptoms had self-medicated. The most commonly used drugs were Paracetamol (85.0\%), Azithromycin (58.0\%), Expectorants (30.0\%), Ivermectin (18.0\%), Doxycycline (16.0\%), Corticosteroids (7.0\%), and Hydroxychloroquine $(4.0 \%)$. The major sources of information about the disease and drugs were pharmacists (46.6\%) and the internet (28.0\%).

Conclusion: There were significant percentages of self-medication during the COVID-19 pandemic, including the drugs without sufficient scientific evidence.

Keywords: Covid-19, Pandemic, Self-medication, Drugs, Healthcare.

(C) 2021 The Authors. Published by Innovare Academic Sciences Pvt Ltd. This is an open access article under the CC BY license (http://creativecommons.org/ licenses/by/4.0/) DOI: http://dx.doi.org/10.22159/ajpcr.2021v14i10.42761. Journal homepage: https://innovareacademics.in/journals/index.php/ajpcr

\section{INTRODUCTION}

Self-medication is the use of medicinal products by individuals to treat self-identified diseases or symptoms. It also involves the intermittent or continuous use of medication prescribed by a physician to address chronic or recurrent illness or symptoms, obtaining medications without a prescription or resubmitting outdated prescriptions to obtain medications, sharing medications with family or friends, or consuming leftover medication, or failing to follow a professional prescription, either by prolonging or interrupting it too soon, or decreasing or raising the originally intended dose [1].

Self-medication encourages patients to be more self-reliant in making decisions about minor disease management. However, on the other hand, it carries dangers such as misdiagnosis, excessive drug dosage, long-term use, drug interactions, and polypharmacy [2].

The healthcare system worldwide has been challenged by the COVID-19 outbreak. Fear and anxiety have crept in as a result of the lack of a specific cure for this viral infection. The general public's perplexity at the issue has resulted in an increase in self-medication, including home remedies, with no established safety or efficacy. Furthermore, recommendations from friends, relatives, neighbors, pharmacists, and prescriptions from other Covid-positive patients have lead to an increase in self-medication [3]. Many people ceased visiting healthcare facilities for medical interventions due to concerns about getting COVID-19 in a hospital setting and the ease with which they can obtain drugs [4]. Self-Medication was exacerbated by the fake news epidemic that accompanied the COVID-19 pandemic as well as the widespread media coverage of any study related to a potential preventive or treatment approach [5]. The present study aims to assess the prevalence of selfmedication for COVID-19 like symptoms during the pandemic.

\section{METHODS}

We performed an online questionnaire-based survey, in May 2021, at SKIMS Hospital, Srinagar, on the use of some drugs that were presumably effective in the prevention or treatment of covid-19. The questionnaire was developed with Google forms, pretested, and sent by email or Whatsapp to 203 people selected by convenience sampling. 35 respondents had answered incompletely. Hence the data of only 168 participants were considered for the study and the rest were excluded. The questionnaire had two sections. Sections one asked questions about various demographic variables such as gender, age, marital status, educational qualification, and employment. Section two asked questions about the respiratory symptoms and drugs used during the COVID-19 pandemic. It also asked questions about the patient's perceptions about drug use. The responses received were anonymized.

\section{Inclusion criteria}

Age above 18 years, can communicate by speaking or writing, willing to participate in the study.

Exclusion criteria

Age below 18 years, cannot communicate by speaking or writing, willing to participate in the study.

Data entry and analysis

Data were entered into a computer, and analysis was done by a combination of manual calculators and online Vassar Stats. Descriptive statistics were used.

\section{RESULTS}

Table 1 shows the demographic characteristics of the study population. $53.0 \%(n=89)$ participants were males and $46.4 \%(n=78)$ females. 
One participant chose not to reveal the gender. The age of $71.4 \%$ $(n=120)$ was below 30 years, $25.6 \%(n=43) 31-60$ years and $3.0 \%$ $(n=5)$ above 60 years. $27.4 \%(n=46)$ were married and $72.6 \%(n=122)$ were unmarried. $0.6 \%(n=1)$ were illiterate, $5.4 \%(n=9)$ had received education up to school level, $44.0 \%(\mathrm{n}=74)$ up to college level and $50.0 \%(\mathrm{~N}=84)$ up to university level. $49.4 \%(\mathrm{n}=83)$ were unemployed, $11.3 \%(\mathrm{n}=19)$ self-employed, $25.6 \%(\mathrm{n}=43)$ private sector employees and $13.7 \%(n=23)$ were government employees. $39.9 \%(n=67)$ were healthcare workers.

Table 2 shows $59.5 \%$ ( $\mathrm{n}=100)$ participants suffered from covid-19 like symptoms. $72.0 \%(\mathrm{n}=72)$ of those who had symptoms got tested for covid-19, out of which $44.5 \%(n=32)$ tested positive.

Table 3 shows that $70.0 \%(\mathrm{n}=70)$ participants had fever, $95.0 \%$ $(n=95)$ headache, 59\% ( $n=59)$ body aches, $34.0 \%(n=34)$ sneezing, $50.0 \%(\mathrm{n}=50)$ sore throat, $32.0 \%(\mathrm{n}=32)$ nasal congestion, $45.0 \%$ $(\mathrm{n}=45)$ cough, $14.0 \% \quad(\mathrm{n}=14)$ breathlessness, and $39.0 \% \quad(\mathrm{n}=39)$ other symptoms. All the participants $(\mathrm{n}=100)$ who got Covid-19 like symptoms took a drug or combination of drugs. $85.0 \%(n=85)$ took paracetamol, $13.0 \%(\mathrm{n}=13)$ ibuprofen, $18.0 \%(\mathrm{n}=18)$ ivermectin, $58.0 \%(\mathrm{n}=58)$ azithromycin, $1.0 \%(\mathrm{n}=1)$ budesonide, $30.0 \%(\mathrm{n}=30)$ cough syrup, $16.0 \%(\mathrm{n}=16)$ doxycycline, $3.0 \% \quad(\mathrm{n}=3)$ penicillins, $4.0 \%(\mathrm{n}=4)$ hydroxychloroquine, $2.0 \%(\mathrm{n}=2)$ remdisivir, $7.0 \%(\mathrm{n}=7)$ dexamethasone, $3.0 \%(n=3)$ famotidine, and $19.0 \%(n=19)$ other drugs.

Table 4 shows that $51.0 \%(n=51)$ of the participants with symptoms, thought that these drugs will prevent or treat covid-19. $49.0 \%(n=49)$ revealed that they usually take these drugs during flu-like symptoms.

Table 1: Demographics

\begin{tabular}{lll}
\hline Variable & No. & \% \\
\hline Gender & & \\
Male & 89 & 53.0 \\
Female & 78 & 46.4 \\
$\quad$ Preferred not to disclose & 1 & 0.6 \\
Age & & \\
Below 30 years & 120 & 71.4 \\
31-60 years & 43 & 25.6 \\
Above 60 years & 5 & 3.0 \\
Marital status & & \\
Married & 46 & 27.4 \\
Unmarried & 122 & 72.6 \\
Educational level & & \\
No education & 1 & 0.6 \\
School level & 9 & 5.4 \\
College level & 74 & 54.0 \\
$\quad$ University level & 84 & 50.0 \\
Profession & & 49.4 \\
Unemployed & 83 & 11.3 \\
Self employed & 19 & 25.6 \\
Private job & 43 & 13.7 \\
Government job & 23 & 39.9 \\
Healthcare worker & & 60.1 \\
$\quad$ Yes & 67 & \\
No & 101 & \\
\hline
\end{tabular}

Table 2: Suffered from symptoms/tests done

\begin{tabular}{lcc}
\hline Variable & No. & \% \\
\hline Suffered from covid-19 like symptoms during pandemic & \\
$\quad$ Yes & 100 & 59.5 \\
$\quad$ No & 68 & 40.5 \\
Got tested for covid & 72 & 72.0 \\
$\quad$ Yes & 28 & 28.0 \\
$\quad$ No & & \\
Test results & 32 & 44.5 \\
$\quad$ Positive & 40 & 55.5 \\
$\quad$ Negative & \\
\hline
\end{tabular}

Table 5 shows the source(s) of information about covid-19 in the study group. $28.0(\mathrm{n}=47)$ got information about the disease and drugs from Internet, $0.6 \%(\mathrm{n}=1)$ radio, $5.4 \%(\mathrm{n}=9)$ television, $2.4 \%(\mathrm{n}=4)$ news papers, $13.1 \%(n=22)$ books/magazines/journals, $8.3 \%(n=14)$ friends, $18.5 \%(\mathrm{n}=31)$ family, $44.6 \%(\mathrm{n}=75)$ pharmacists/healthcare professionals, and $17.7 \%(n=29)$ from various other sources.

\section{DISCUSSION}

Self-medication is a global phenomenon. It has traditionally been defined as "the taking of medicine by oneself." On one's own initiative, without consulting a doctor. Families, friends, neighbors, the pharmacist, suggestions from an advertisement in newspapers, TV or magazines are common sources of information [6]. Self-medication, when done correctly, can be beneficial to an individual's health and is recognized by the WHO as a kind of self-care [7]. Incorrect selfdiagnosis, delays in seeking medical advice when needed, severe adverse reactions, dangerous drug interactions, incorrect method of administration, incorrect dosage, incorrect choice of therapy, masking of severe disease, and the risk of dependence and abuse are

Table 3: Symptoms and drug usage

\begin{tabular}{|c|c|c|c|}
\hline Symptoms & No. & & $\%$ \\
\hline Fever & 70 & & 70.0 \\
\hline Headache & 95 & & 95.0 \\
\hline Body aches & 59 & & 59.0 \\
\hline Sneezing & 34 & & 34.0 \\
\hline Sore throat & 50 & & 50.0 \\
\hline Nasal Congestion & 32 & & 32.0 \\
\hline Cough & 45 & & 45.0 \\
\hline Breathlessness & 14 & & 14.0 \\
\hline Others & 39 & & 39.0 \\
\hline \multicolumn{4}{|l|}{ Any drugs taken } \\
\hline Yes & 100 & & 100.0 \\
\hline No & 0 & & 0 \\
\hline \multicolumn{4}{|l|}{ Drug (S) taken } \\
\hline Paracetamol & 85 & & 85.0 \\
\hline Ibuprofen & 13 & & 13.0 \\
\hline Ivermectin & 18 & & 18.0 \\
\hline Azithromycin & 58 & & 58.0 \\
\hline Budesonide & 1 & & 1.0 \\
\hline \multicolumn{4}{|l|}{ Inhalations } \\
\hline Cough syrup & 30 & & 30.0 \\
\hline Doxycycline & 16 & & 16.0 \\
\hline Penicillins & 3 & & 3.0 \\
\hline Hydroxychloroquine & 4 & & 4.0 \\
\hline Remdisivir & 2 & & 2.0 \\
\hline Dexamethasone & 7 & & 7.0 \\
\hline Famotidine & 3 & & 3.0 \\
\hline Others & 19 & & 19.0 \\
\hline \multicolumn{4}{|c|}{ N.B: Due to multiple options respondents could select, sum of \%age is not 100} \\
\hline \multicolumn{4}{|c|}{ Table 4: Perceptions about drugs used } \\
\hline \multicolumn{2}{|l|}{ Perception } & No. & $\%$ \\
\hline \multicolumn{2}{|c|}{ Will prevent/treat covid-19 } & 51 & 51.0 \\
\hline \multicolumn{2}{|c|}{ Usually take these drugs for such symptoms } & 49 & 49.0 \\
\hline
\end{tabular}

Table 5: Source of information about the disease/drugs

\begin{tabular}{lll}
\hline Source & No. & $\mathbf{\%}$ \\
\hline Internet & 47 & 28.0 \\
Radio & 1 & 0.6 \\
TV & 9 & 5.4 \\
News papers & 4 & 2.4 \\
Text Books/Journals & 22 & 13.1 \\
Friend & 14 & 8.3 \\
Family & 31 & 18.5 \\
Pharmacist & 75 & 44.6 \\
Others & 29 & 17.7 \\
\hline N.B: Due to multiple options respondents could select, sum of \%age is not 100
\end{tabular}


all potential risks of self-medication [8]. The COVID-19 epidemic is wreaking havoc around the globe. As of July 22, 2021, 191,773,590 confirmed cases of COVID-19, including 4,127,963 deaths have been reported to World Health Organization [9]. The pandemic has caused challenges to healthcare systems around the world since it requires novel treatment and prevention strategies to deal with the impact of the pandemic. Medical professionals and patients are both battling with the "unknown." The pandemic has led to a panic-driven, almost compulsive, reliance on various social media platforms among the general people, resulting in disinformation regarding pharmaceuticals and increased self-medication, including home remedies, with no documented safety or efficacy. The present study aims to assess the prevalence of selfmedication for COVID-19 like symptoms.

We found that all the participants who had covid-19 like symptoms selfmedicated. $51.0 \%$ of participants used the drugs to prevent or treat the disease/symptoms and $49.0 \%$ admitted that they usually take these drugs for such symptoms. The major symptoms were fever $(70.0 \%)$, headache (95.0\%), body aches (59.0\%), sore throat (50.0\%) and cough (45.0\%). The most commonly used drugs were Paracetamol (85.0\%), Azithromycin (58.0\%), Expectorants (30.0\%), Ivermectin (18.0\%), Doxycycline (16.0\%), Corticosteroids $(7.0 \%)$, Hydroxychloroquine $(4.0 \%)$ and Famotidine $(3.0 \%)$. The major sources of information about the disease and drugs were pharmacists $(46.6 \%)$ and the internet $(28.0 \%)$.

We also found self-medication more prevalent in males (71.9\%), above 60 years age $(100 \%)$, those with Post-graduate qualification (80.9\%), and government employees (73.9\%), as compared to other comparative groups. There was no difference in self-medication prevalence between healthcare workers and others.

As per a Google trends study, since the global corona virus pandemic was declared in 2019, there has been a relative increase in the number of people searching for information about self-medication of various ailments, which might also indicate that there has been an increased interest in the number of people browsing about self-medication of various ailments during the pandemic [10].

In a study on self-medication practices during the Covid-19 pandemic, it was found that the majority of respondents self-medicated with Acetaminophen, Ibuprofen, Azithromycin, Penicillin, Antiretrovirals, and Hydroxychloroquine for flu-like symptoms [5]. One study found low self-medication during the pandemic [11].

In an editorial commentary, Molento has expressed the concerns about self-medication with ivermectin during the Covid-19 pandemic as it is advocated over broad audiences at official pharmaceutical homepages, YouTube channels, and TV interviews. There is strong evidence showing that people self-medicate using antibiotics such as azithromycin and Hydroxychloroquine [12]. Iftikhar et al. found that About $15 \%$ of the participants took conventional and homeopathic medicines prophylactically in order to lower the risk of being infected with the coronavirus. Paracetamol was the most commonly used drug, followed by Fexofenadine, Zinc, Montelukast, and Ivermectin. People also took antibiotics including Azithromycin, Doxycycline, Amoxicillin, Levofloxacin, Linezolid, and Cephalosporins [13].

\section{Limitations}

In our study, there are some limitations. The validity of our findings relies primarily on the accuracy of responses. We tried to minimize recall bias by using a well-structured pre-validated questionnaire. Another limitation of this study is the limited sample size. The convenience sampling method used in the study has the possibility of under-or over-representation of the population and the results of the survey can not be generalized to the population as a whole. The design of the study does not ensure that the study population is representative of the general population

\section{CONCLUSION}

Self-medication is common in both the developed as well as developing countries. The growth of information and communication has resulted in easy access to medical knowledge. Easy access to drugs, the influence of advertisements and previous experience of treating similar illness has influenced the practice of self-medication. During the current pandemic, self-medication for covid-19 like symptoms is widespread for a variety of reasons. Continuous awareness and sensitization about the risks of self-medication are warranted.

\section{ACKNOWLEDGMENT}

The authors wish to thank all those who participated in the study.

\section{AUTHORS` CONTRIBUTIONS}

Dr. Shakeel is the one who conceived the idea, formed the questionnaire, compiled and analyzed the data, and wrote the manuscript. Danish converted the offline questionnaire into an online survey, assisted in collection, tabulation and analysis of data. Dr. Zulfkar collected the data.

\section{CONFLICT OF INTEREST}

None.

\section{AUTHORS`FUNDING}

None.

\section{REFERENCES}

1. Mir SA, Ahangar J, Shakeel D. Comparative assessment of antibiotic self-medication practices among under-graduate medical students and general population. Int J Res Med Sci 2019;7:4563-7.

2. Hughes CM, McElnay JC, Fleming GF. Benefits and risks of self medication. Drug Saf 2001;24:1027-37.

3. Tikoo R. Self-medication for Covid Has Turned Disastrous. Families Must Not Assume Doctors' Role. Available from: https://www.theprint. in/opinion/self-medication-for-covid-has-turned-disastrous-familiesmust-not-assume-doctors-role/663593.

4. Wong LE, Hawkins JE, Langness S, Murrell KL, Iris P, Sammann A. Where are all the patients? Addressing covid-19 fear to encourage sick patients to seek emergency care. NEJM Catal Innov Care Deliv 2020;10:193.

5. Quispe-Cañari JF, Fidel-Rosales E, Manrique D, Mascaró-Zan J, Huamán-Castillón KM, Chamorro-Espinoza SE, et al. Selfmedication practices during the COVID-19 pandemic among the adult population in Peru: A cross-sectional survey. Saudi Pharm J 2021;29:1-11.

6. Bennadi D. Self-medication: A current challenge. J Basic Clin Pharma 2014;5:19-23.

7. World Health Organization. The Role of the Pharmacist in Self-care and Self-medication. Geneva: Hangue, World Health Organization; 1998.

8. Ruiz ME. Risks of self-medication practices. Curr Drug Saf 2010;5:315- 23 .

9. World Health Organization. WHO Coronavirus (COVID-19) Dashboard. Available from: https://www.covid19.who.int.

10. Onchonga D. A Google trends study on the interest in self-medication during the 2019 novel coronavirus (COVID-19) disease pandemic. Saudi Pharm J 2020;28:903-4.

11. Tandon T, Dubey AK, Dubey S, Arora E, Hassan MN. Effects of COVID-19 pandemic lockdown on medical advice seeking and medication practices of home-bound non-COVID patients. J Educ Health Promot 2021;10:28.

12. Molento MB. COVID-19 and the rush for self-medication and selfdosing with ivermectin: A word of caution. One Health 2020;10:100148.

13. Ahmed I, Hasan M, Akter R, Sarkar BK, Rahman M, Sarker S, et al. Behavioral preventive measures and the use of medicines and herbal products among the public in response to COVID-19 in Bangladesh: A cross-sectional study. PLoS One 2020;15:e0243706. 